\title{
Performance of Office Workers Under Office Sounds and Various Enclosure Conditions in Open Workplaces
}

\author{
Heakyung Yoon \\ Hongik School of Architecture, Hongik University, Seoul, Korea
}

http://dx.doi.org/10.5659/AIKAR.2013.15.1.9

\begin{abstract}
Effects of physical attributes of workstation enclosures on the performance of office workers with different difficult levels of office tasks and moods are presented. Performance scores in complex tasks were expected to increase with greater workstation enclosures while those in simple tasks would be the same. Mood ratings were expected to be higher in lower workstation enclosures. Performance of 102 college students on ambient office sounds ( $45 \mathrm{dBA}$ ) with office tasks were measured for 100 minutes under three different workplace enclosures: (1) four foot partitions on two sides; (2) six foot partitions on three sides; and (3) a fully enclosed workstation with eight foot partitions. The tasks were to memorize a paragraph with 130 words (complex task) and to search phone numbers (simple task). The complex task performance in the fully enclosed workstation was increased compared to that in the workstation with four foot partitions ( $\mathrm{p}$ $<0.001)$ and to that in the workstation with six foot partitions $(\mathrm{p}<0.05)$. However, occupants in the fully enclosed workstation with office sounds without speech generally gave higher mood ratings. It indicates that closed individual offices may offer important contributions to collaborative work as well as individual productivity. These findings would help design community revise open plan design to increase collaboration among office workers.
\end{abstract}

Keywords: Performance, Office Worker, Open Workplace, Task Difficulty

\section{INTRODUCTION}

Improved individual productivity and stimulated collaboration have been objected in open workplace design. Since the early 1990 s, the open workplace has reappeared due to an effort to encourage collaboration between workers in companies or institutes (Horgen, Joroff et al., 1999; Brill, 2001). Many companies have realized that it is crucial to use all of each worker's knowledge in combination with all of the knowledge of his or her co-workers in order to compete with other companies in an integrated manner. The open workplace surely provides such an environment for sharing knowledge informally and naturally

\footnotetext{
Corresponding Author : Heakyung Yoon, Assistant Professor

Hongik School of Architecture, Hongik University

94 Wowsan-ro, Mapo-gu, Seoul 121-791, Korea

Tel : +82 23203030 e-mail : yoonh@hongik.ac.kr
}

This research was supported by Basic Science Research Program through the National Research Foundation of Korea(NRF) funded by the Ministry of Education, Science and Technology(20120003544).

The author gratefully acknowledges the great assistance of Prof. Loftness and students from the Building Performance \& Diagnostics program at the Carnegie Mellon University in the experiment.

This is an Open Access article distributed under the terms of the Creative Commons Attribution Non-Commercial License (http://creativecommons. org/licenses/by-nc/3.0/) which permits unrestricted non-commercial use, distribution, and reproduction in any medium, provided the original work is properly cited.
(Becker \& Sims, 2001; Hua, Loftness, Heerwagen, \& Powell, 2011).

\subsection{Noise in Open Workplace}

Continuous complaints about the noise in the open workplace have been the main problem in spite of the many advantages of the open workplace such as the flexibility to change the workplace setting, a lower initial construction cost than the closed workplace, and the sharing of knowledge between workers (Memoli, 1990). The International Facility Management Association in 1997 said 58\% of average office environments in United States or Canadian companies were open plan, 36\% were enclosed offices, and 6\% were bullpen design. According to the survey results of the American Society of Interior Design in 1996, noise in the open workplace has contributed to $71 \%$ of overall workplace distractions. It is questionable how distracted work environment can bring better performance of office workers.

\subsection{Characteristics of Noise and Its Effects on Office Productivity}

Sound in workplaces has been reported to be noise to occupants when it is unwanted even though it is not loud, unexpected, uncontrolled, happening at the wrong time, or containing unwanted information such as an adjacent telephone conversation (ASHRAE, 2001). Most office sounds such as conversations and the sound of copier machines are below $85 \mathrm{dBA}$, which is the regulated sound level of Occupational Safety and Health Administration to prevent hearing loss in the workplace with eight hours of exposure in a day. Therefore, the sound level in most offices does neither contribute to 
critical health problems such as hearing loss nor bring performance differences (Witterseh, 2001).

Sound, however, seems to play a key role in office productivity. According to the survey results of ASID (American Society of Interior Design) in 1996, 70\% of the respondents indicated their productivity would increase if their offices were less noisy, implying better sound quality if the office sound contained speech and/ or the sounds of office equipments, not sound levels. The results correspond to other field assessments about office noise and satisfaction, in which $54 \%$ said they were bothered often by noise, especially by people talking and telephones ringing (Sundstrom, Town, Rice, Osborn, \& Brill, 1994). It appears that if acoustic problems related to productivity could be dealt with properly, they would not be problems anymore in open workplaces.

\subsection{Acoustic and Visual Privacy in Open Workplace}

Acoustic problems in open workplaces are called predominantly speech privacy problems but with and without speech. Architectural acoustic consultants have found occupants were unsatisfied with their own work environments when they heard their co-workers' telephone conversations and movements as well as sounds from office peripherals such as printers and fax machines. Mobile phones, as well as speaker phones used in teleconferences have been used increasingly in our work environments in the last decade.

Acoustical privacy, however, seems to be very related with visual privacy. Cerami in 1979 reported office workers' satisfaction increased depending on the order of layout A, B, C, D in Figure 1. In layout $\mathrm{D}$, with less visual contact and more barriers in workstations, occupants were the most satisfied although their sound levels in the layout A, B, C, D were the same. Occupants in layout type A usually complained more about the acoustic problems in their working environments than those in other layout types. It seemed occupants expressed their visual privacy dissatisfaction as acoustic problems as shown other workplaces frequently. Regrettably, most studies on acoustical and/ or visual privacy in workplaces have not moved beyond initial surveybased research.

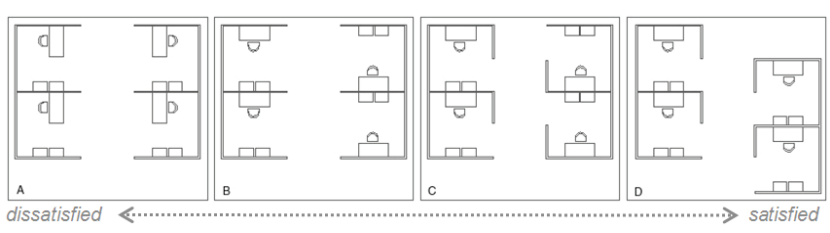

Figure 1. Visual privacy by workstation layouts brings satisfaction difference. Layout $\mathrm{D}$ was the most satisfactory type to occupants and the satisfaction of occupants decreased more in order of layout C, B and A according to Cerami's field experience in 1979.

Research on the performance of office workers with office tasks under various office sound conditions is needed. Moreover, since it is not clear if acoustic and/or visual privacy problems stem from sound quality itself, or from visual distractions in different physical settings, such as workstations with different partition heights, investigations into the different enclosure conditions are also needed.

\section{EFFECTS OF TASK DIFFICULTIES ON PERFORMANCE}

Numerous types of tasks have been conducted in offices and each type has also various levels of task difficulties. Physiological evidence has been reported regarding different working loads. Electroencephalograms (EEG) conducted in the working memory load research of Gevins et al. in 1998 showed that theta waves in the cerebral cortexes of subjects' brains were more active for the moderate and high load level tasks than for the low load level tasks, while alpha waves decreased between low and high level tasks. This may suggest that the performance of workers differ according to the task difficulties, because they use different parts of their brains. Among many aspects of tasks, task difficulties have been considered here for the office performance of white collar office workers are desired to be improved and their works such as reading, writing, and analyzing are not simple tasks.

\subsection{Noise Effects in Performance}

Sound has been known as a stressor that stimulates people. ${ }^{1}$ It brings out increased performance to a certain degree, but decreased when the sound causes distraction (Loewen \& Suedfeld, 1992). This has been assumed by the Yerkes-Dodson $\mathrm{law}^{2}$, by which a bell shape relation lies between performance and arousal and in which the optimal performance point in difficult tasks is lower than that in simple tasks as shown in Figure 2 (Yerkes \& Dodson, 1908).

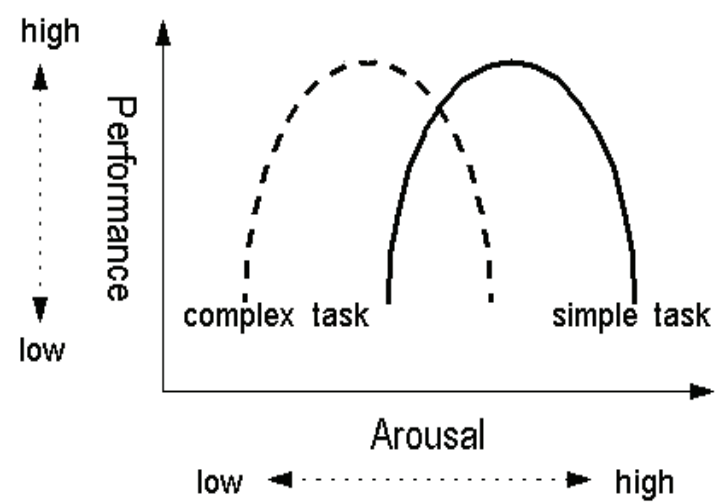

Figure 2. Diagram of the Yerkes-Dodson law with complex and simple tasks. Performance increases to a certain degree and decreases after that degree. The optimal point in the bell shape relation between performance and arousal with a complex task appears lower than that with a simple task.

\footnotetext{
${ }^{1}$ Jones, D. M. and Smith, A. P. (1992). Handbook of Human Performance. pp. 1-28. London; San Diego: Academic Press.

2 The Yerkes-Dodson law means an empirical relationship between arousal and performance, originally suggested by psychologists R. M. Yerkes and J. D. Dodson in 1908. This law shows that performance increases with physiological or mental arousal by some point. When levels of arousal become too high, performance decreases. The process is often illustrated graphically as a bell-shaped curve which increases and then decreases with higher levels of arousal.
} 


\subsection{Task Difficulty Scales}

In relation to the Yerkes-Dodson law, the different brain pattern findings of Gevins et al. in $1998^{3}$ seem to suggest that the performance of workers differ according to the difficulty of the tasks for they use different parts of their brains.

NASA Task Load Index (Hart \& Staveland, 1988) and CooperHarper Scale (Hancock, 1987) are known as validated task load indexes. Both of NASA Task Load Index and the CooperHarper scale were used in this research to test the task difficulties. The rating 1 means 'very easy difficulty level' and the rating 10 'impossible level to accomplish the task' in the Cooper-Harper's 1-10 scale, while the NASA Task Load Index method assesses work load on five 7-point scales; 'mental demand,' 'physical demand,' 'temporal demand,' 'performance, 'effort,' and 'frustration.

\section{PROBLEMS IN THE EXISTING LITERATURE}

\subsection{Unrealistic Office Sounds}

It is difficult to find experiments with realistic office sounds. Much laboratory literature has shown workers who work with steady state sound could perform better than those who work with intermittent sound (Jones, Madden, \& Miles, 1992; Salame, 1982). However, sound conditions in real offices are likely to be combined more than two sounds such as constant HVAC (Heating Ventilation and Air-Conditioning) sounds and occupants' conversation, or sounds from office peripherals and telephone rings. One consequent problem in the use of realistic office sounds, therefore, is what exact sound components are encountered in the general office.

A several studies have used realistic office sounds; for instance, Loewen and Suedfeld (1992), and Witterseh (2001). Loewen has used real recorded office sounds while Witterseh used simulated office sounds. In Loewen's experiments, conversations with full sentences were not included. Considering co-workers' conversations have been reported to be one of the most disturbing sounds in open workplaces ${ }^{4}$, Loewen's experiment is incomplete. In Witterseh's experiment, three different temperature conditions were used, combined with two sound conditions, quiet ( $35 \mathrm{dBA}$ ) versus ambient office sound ( $55 \mathrm{dBA})$ conditions. Most of the findings were focused on performance differences under the different temperature conditions unfortunately for this literature review. There was no statistical difference between the two sound conditions (without different levels of office task difficulty) possibly because he used two different sound qualities and sound levels. Although Jones and Salame used pure tones, their results have been supported by the office sound experiments of Loewen and Suedfeld in 1992 in some respects. Performance in a simple number identification task under masked sound has been reported to be better than under unmasked sound although there was no

\footnotetext{
3 The electroencephalograms (EEG) conducted in the working memory load research showed that theta in the cerebral cortexes of subjects was larger for the moderate and high load level tasks than for the low load level tasks, while alpha decreased between low and high level tasks.

4 ASHRAE (American Society of Heating, Refrigerating and AirConditioning Engineers, Inc.) in 2001 notified sound becomes noise when it is too loud, it is unexpected, it is uncontrolled, it happens at the wrong time, it contains pure tomes, it contains unwanted information or is distracting such as an adjacent telephone conversation or undesirable music, etc.
}

statistical significance. However, the mean performance score of complex tasks under quiet sound was the highest.

\subsection{Simple Task Types such as Clerical Tasks}

Most studies concerning office sounds have used tasks such as memory, arithmetic or attention tasks, without consideration of task difficulties. Simulated office tasks have only measured clerical work performance $(\mathrm{Ng}, 1989)$. One kind of task has various levels of difficulties. For example, two digit and nine digit serial recall tasks cannot be said to have the same level of task difficulty. In current open workplace settings, knowledge workers have been located with the intention of stimulating informal knowledge sharing between workers. Clerical tasks are not the main office chores for them. Therefore, we need to know more about the effects of different levels of office task difficulty on workers' performance differences.

Consequently, the main observed problem in the abovementioned research studies is that there are few performance comparisons with realistic office sounds and different levels of office task difficulty. Therefore, performance differences between various office tasks other than clerical tasks need to be known.

\subsection{Simple Categorization of Workplace Settings}

A simple categorization such as an open or an enclosed office is inappropriate nowadays because many current office settings are hybrid types of open and enclosed offices. For example, enclosed offices often have an open meeting area in front of their workspace or they are dynamic open work settings that can be changed from open work settings to a closed hub using re-stackable panels, a door, an individual ceiling However, many studies have not considered the varieties (Block \& Stokes, 1989; Brill, 2001). Therefore, the effects of the various state-of-the-art materials and settings in open workplaces on individual and collaborative performance need to be investigated.

\section{EXPERIMENT}

From the previous literature reviews on the task difficulty and performance under different office sound conditions compared with under quiet conditions, we may assume that task difficulty and different sound conditions and/or different workplace settings result in different performance rates of white collar workers.

In the view of architectural designers, the type of workstation is the first design consideration. For example, high or low partitions are selected and then the level of acoustic treatment is considered for each partition even though the height of partitions and the level of their acoustic treatment works together to deliver noise reduction in the workstation. In most cases, occupants in workplaces do not see the acoustic treatment in partitions because the major acoustic treatment is inside the partitions. If they see a partition with fabric cover, it may or may not have acoustic layers between the panels of the partition. Therefore, if the sound level in a workstation with 6 foot partitions with acoustic treatment is the same as that without acoustic treatment, occupants in the two workstations will perceive that each workstation has the same condition. That perception actually means occupants perceive the acoustic privacy from their visual privacy in their workstations. Therefore, under the same level of sound, people involved in complex tasks might perform better 
with more private work settings. From this observation, the first and second hypotheses have been drawn.

Acoustic privacy problems have been identified as speech privacy problems for occupants in workplaces are bothered mainly by coworkers' telephone conversations or conversations with other coworkers (ASID, 1996). However, intruding sound without speech also has been reported as distracting sounds that decrease workers' performance (Sundstrom et al., 1994; ASHRAE, 2001). Therefore, the same sound with and without speech may cause a different rate of performance, which leads to the third and the fourth hypotheses.

In many self-reported productivity reports and surveys, respondents said that their satisfaction would be better and their distraction and annoyance in work would be less with higher privacy work settings (Sundstrom et al., 1994; ASID, 1996). This leads to the fifth and sixth hypotheses.

Open workplaces have been reported as better for knowledge sharing between knowledge workers than closed offices (Davenport \& Prusak, 1998; Becker and Sims, 2001). Therefore, informal knowledge sharing would eventually deliver better timeefficiency to produce competitive products for organizations. This has been one of the main attractions to adopt open workplaces as major future office types. Therefore, this leads to the sixth hypothesis.

Hypothesis 1) Performance scores in complex tasks will increase with greater workstation enclosures.

Hypothesis 2) Performance scores in simple tasks will be the same regardless of the different workstation enclosures.

Hypothesis 3) Performance scores in complex tasks will be higher under office sound without speech than those under office sound with speech.

Hypothesis 4) Performance scores in simple tasks will be the same regardless of the different characteristics of office sounds.

Hypothesis 5) Distraction and annoyance as a psycho-social index will increase under office sound with speech, and with less workstation enclosures.

Hypothesis 6) Sociableness, which is one of the mood scales in the questionnaire, will increase under office sound with speech, and with less workstation enclosures.

\subsection{Method}

\section{Design}

The experiments were executed as a $3 \times 2$ mixed subject design: 3 different workstations (four foot partitions on two sides; seated privacy with six foot partitions on three sides; and a fully enclosed workstation with eight foot partitions, a door and a ceiling as shown in Table 1.) and two different acoustic conditions (ambient office sounds with and without speech at $45 \mathrm{dBA}$ background sound levels at the receiver). $45 \mathrm{dBA}$ is recommended as the background sound level for open office workplaces (Egan, 2007). A betweengroup structure for the workstations with three different partitions was used and a within group structure for the two different sound and two different tasks was used. One hundred and twenty nine subjects at a university (median age 23, range 19-55; 61 male, 68 female) participated the experiments. All of them speak and read English fluently without any difficulties of understanding, and sixty-none were native speakers of English. None of subjects had hearing related diseases.
Table 1. Three different workstations (four foot partitions on two sides; six foot partitions on three sides; and a fully enclosed workstation with eight foot partitions, a door and a ceiling) selected for the experiment.

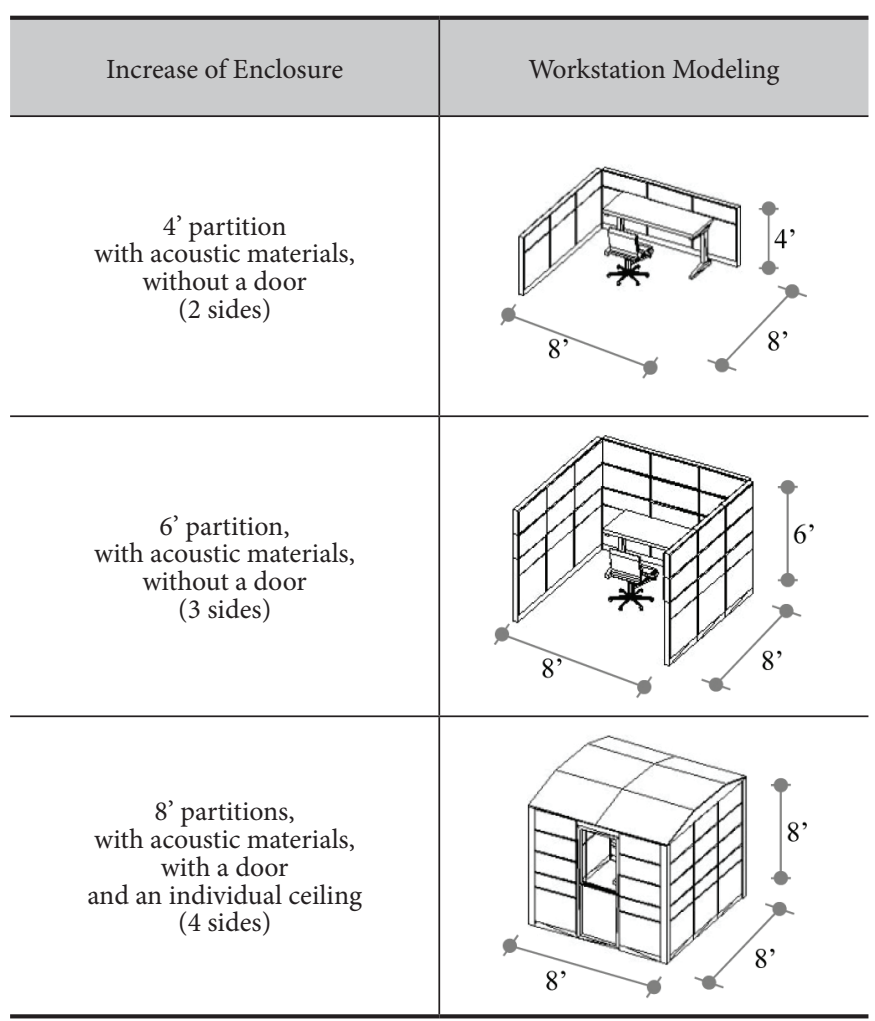

\section{Procedure}

Before the experiment began, subjects were asked to fill out the 'Questionnaire a' to assess their personal information and their mood before they are exposed. Then, they have 20 minutes to be habituated to the background sound (Banbury \& Berry, 1997). At that time, they can also adjust their clothing and the chair height to feel comfortable. During that time, they can practice the following tasks. After 20 minutes of habituation, two tasks are given in Latin square order and subjects are asked to fill out 'Questionnaire b' after each task. The 'Questionnaire a and b' asked 'how she/he feel' in 14 moods: satisfied, alert, accommodating, playful, relaxed, disturbed, irritated, tired, cooperative, sociable, self-controlled, tense, annoyed, distracted. The mood ratings followed the mood scale of Swedish Performance Evaluation System by Gameberale et al in 1989.

For the phone book task as a simple task, 10 minutes was given while 15 minutes was given for the memory prose task as a complex task. After they complete the tasks, another session with a different background sound condition was repeated once more with 20 minute habituation and two tasks. During the second 20 minute habituation time, subjects could choose more practice or other readings in relaxed conditions.

\subsection{Results}

The total number of subjects in this analysis was 69 who were native speakers of English among 102 subjects, for the performances of only native speakers of English showed statistically significant differences. Data obtained from the questionnaires and performance tests were analyzed using two-way analysis of 
variance (ANOVA) and general multivariate analysis of variance (MANOVA) in Minitab 13.

The scores of complex tasks were significantly higher when subjects were located in the workstation with full height partitions (full enclosure) than in the workstation with 4 foot partitions $(\mathrm{p}<$ $0.001)$ and in the workstation with 6 foot partitions $(\mathrm{p}<0.05)$ at 45 $\mathrm{dBA}$ background sound levels as shown in Figure 3. The possible maximum score of the complex task was 13 . No significant effect for complex task in other conditions and simple tasks was found.

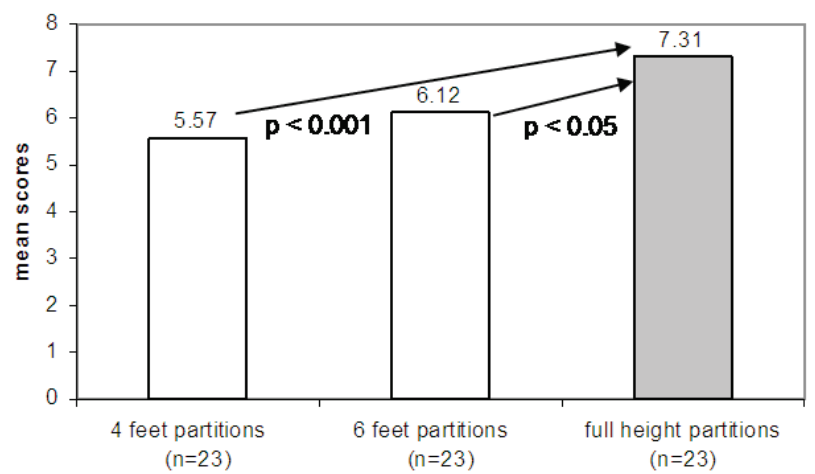

Figure 3. Complex task (memory prose task) scores in three different partitions at $45 \mathrm{dBA}$ back-ground sound levels among native speakers of English $(n=69)$.

Regarding distraction, subjects in the first mood rating were affected significantly, by the combination of workstation and sound types as shown in Figure $4(\mathrm{p}=0.049)$. Task types distracted subjects statistically significantly in the second $(p=0.004)$ and in the third mood ratings $(p=0.021)$. In the second mood rating, the combination of workstation and sound and task types also distracted subjects significantly $(\mathrm{p}=0.008)$. The combination of workstation and task types affected subjects' rating of distraction significantly in the fifth mood rating $(\mathrm{p}=0.018)$. The average rating of distraction was the highest in the workstation with 6 foot partitions exposed to office sounds without speech.

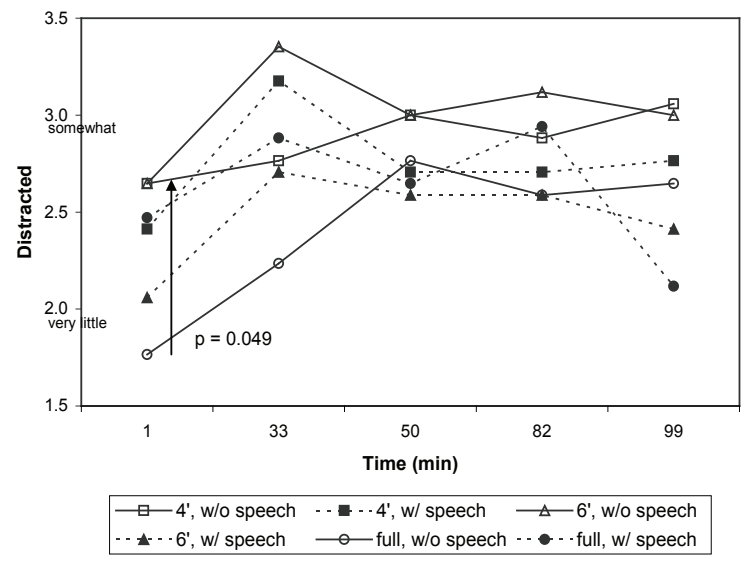

Figure 4. Distraction during the 100 minute experiment.

Subjects' annoyance in the third mood rating, right after the first session was finished, was affected significantly by task types $(p=0.041)$. The combination of workstation and task types also showed a significant effect on annoyance ratings in the fourth mood rating $(\mathrm{p}=0.023)$. It was observed impressionistically that subjects in the workstation with 6 foot partitions exposed to office sounds without speech rated the highest on annoyance. However, those in the workstation with full height partitions exposed to office sounds without speech rated the lowest for annoyance as shown in Figure 5.

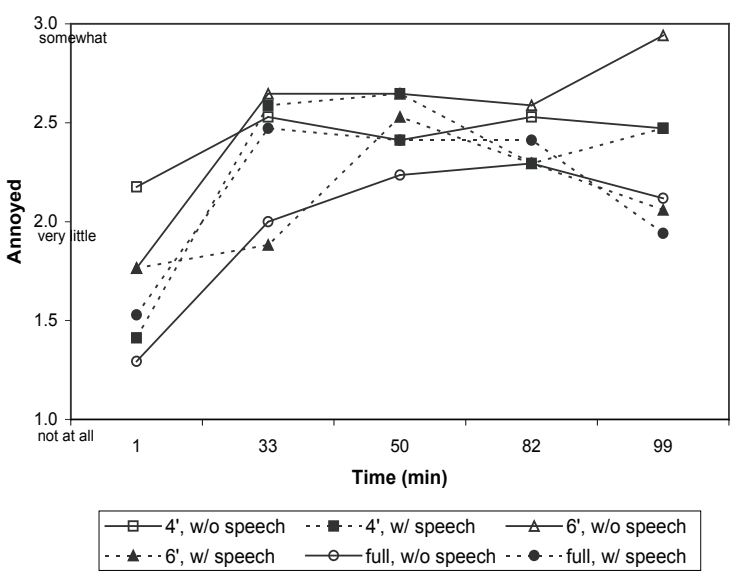

Figure 5. Annoyance during the 100 minute experiment.

Task types appear to play an important role generally for the ratings of psycho-social factors, distraction and annoyance. Subjects in the workstation with 6 foot partitions exposed to office sounds without speech expressed high annoyance and distraction. So, the 5th hypothesis, 'Distraction and annoyance as a psycho-social index will increase under office sound with speech, and with less workstation enclosures', is rejected here.

In the first mood rating, the sociableness of subjects showed significant statistical difference in the combination of workstations and sound types $(\mathrm{p}=0.047)$ as shown in Figure 6 . Their sociableness in the combination of sound and task types were also affected significantly in the first mood rating $(\mathrm{p}=0.025)$. Subjects in the workstation with full height partitions exposed to office sounds without speech generally showed high ratings in the representative mood dimensions of social orientation ('accommodating' and 'cooperative' moods) and social interaction motive ('playful' and 'sociable', moods). This may suggest white collar workers have better social orientation and social interaction motives in the workstation with full height partitions under office sounds without speech.

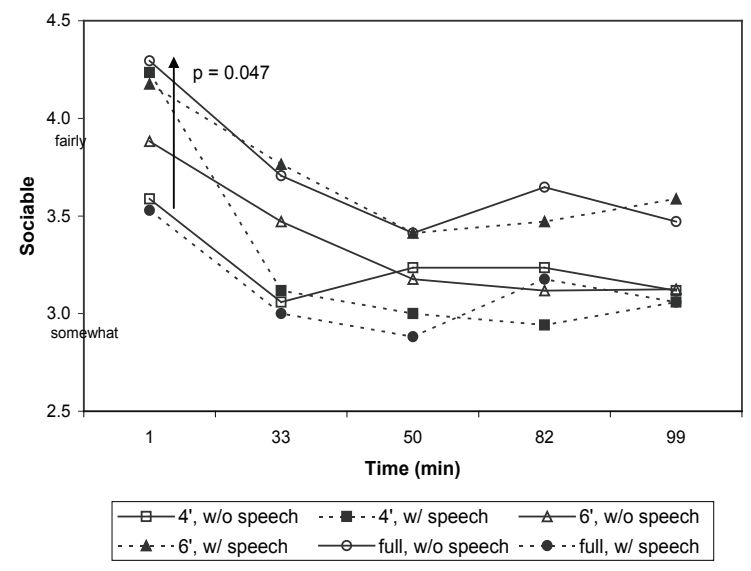

Figure 6. Sociableness during the 100 minute experiment. 
Among the seven hypotheses tested in the experiment, therefore, the accepted hypotheses are:

Performance scores in complex tasks will increase with greater workstation enclosures.

Performance scores in simple tasks will be the same regardless of the different workstation enclosures.

Performance scores in simple tasks will be the same regardless of the different characteristics of office sounds.

The rejected hypotheses are:

Performance scores in complex tasks will be higher under office sound without speech than those under office sound with speech.

Distraction and annoyance as a psycho-social index will increase under office sound with speech, and with less workstation enclosures.

Social-orientation, which is one of the mood scales in the questionnaire, will increase under office sound with speech, and with less workstation enclosures.

\subsection{Discussion}

There was a significant effect for complex tasks in workstation types for native speakers of English only. The tasks were presented in English and the performance results of nonnative speakers of English did not show statistically significant differences under various sounds and workplace conditions, although all of subjects have no difficulties in reading and understanding English. In global work environments, it may imply the performance of white collar workers who are native speakers are affected more by background sounds and workplace conditions.

From the results of the experiment, it may be assumed that when white collar office workers conduct simple tasks, neither the height of partitions nor the characteristics of their background sound impair their individual performance. However, when they need to conduct complex tasks, a workstation with high partitions would be better for high performance.

Based on the finding that there was no significant difference with two sounds (office sounds without speech and office sounds with speech), we may assume as long as the background sound level is $45 \mathrm{dBA}$, speech does not impair individual performance. It is clear from the results that enclosure is the key to complex task performance and absorption is the key to keeping background sound levels below $45 \mathrm{dBA}$ at the receiver.

Regarding mood measurements, the fourteen moods that were rated five times in questionnaires during the experiment were analyzed. Twelve moods among the fourteen are from six representative dimensions of mood; pleasantness, activation, social orientation, tension, social interaction motive, and control. 'satisfied' and 'irritated' are from the mood dimension of pleasantness, 'alert' and 'tired' from activation, 'disturbed' and 'tense' from tension, 'accommodating' and 'cooperative' from social orientation, 'playful' and 'sociable' from social interaction motive, 'relaxed' and 'self-controlled' from control. 'annoyed' and 'distracted' are psycho-social factors.

In the representative mood dimension of pleasantness, subjects were affected significantly by the combined effect of workstation and sound types for their satisfied mood in the second mood rating $(\mathrm{p}=0.035)$ and by task types for their irritated mood in the third mood rating $(\mathrm{p}=0.032)$.

In the representative mood dimension of activation, subjects were affected significantly by task types for their tired mood in the fifth mood rating $(\mathrm{p}=0.014)$. There was no significant effect in the alert rating.

In the representative mood dimension of tension, subjects were affected significantly by task types for their disturbed mood in the third mood rating $(\mathrm{p}=0.028)$ and by workstation types for their tense mood in the first mood rating $(\mathrm{p}=0.022)$.

In the representative mood dimension of social orientation, subjects were affected significantly by the combined effect of workstation and sound types in the fifth mood rating for their accommodating $\operatorname{mood}(\mathrm{p}=0.023)$. They were also affected by the combined effect of sound and task types in the fourth mood rating for their accommodating $\operatorname{mood}(\mathrm{p}=0.035)$ and in the third mood rating for their cooperative $\operatorname{mood}(p=0.016)$. Speech and the workstation with 6 foot partitions returned low ratings in social orientation. It may be assumed from this result, combined factors rather than single factors in workplaces affect the social orientation of white collar workers.

In the representative mood dimension of the social interaction motive, subjects were affected significantly by the combined effect of workstation and sound types in the third mood rating (p $=0.015)$ and by task types in the fourth mood rating $(\mathrm{p}=0.016)$ for their playful mood. In the first mood rating, the sociableness of subjects showed significant statistical difference in the combination of workstations and sound types $(\mathrm{p}=0.047)$. Their sociableness in the combination of sound and task types were also affected significantly in the first mood rating $(\mathrm{p}=0.025)$.

Subjects in the workstation with full height partitions exposed to office sounds without speech generally showed high ratings in the representative mood dimensions of social orientation and social interaction motive. This may suggest white collar workers have better social orientation and social interaction motives in the workstation with full height partitions under office sounds without speech.

In the representative mood dimension of control, subjects were affected significantly by the combined effect of workstation and sound types for their relaxed mood in the first mood rating $(\mathrm{p}=0.027)$ and in the second mood rating $(\mathrm{p}=0.039)$ for their irritated mood, and in the third mood rating $(\mathrm{p}=0.024)$, in the fourth mood rating $(\mathrm{p}=0.026)$ and in the fifth mood rating $(\mathrm{p}=0.040)$ for their self-controlled mood. The combination of workstation and sound and task types in the fourth mood rating made subjects feel significantly self-controlled $(\mathrm{p}=0.010)$. Male subjects appeared more relaxed than females $(\mathrm{p}=0.021)$.

Task types appear to play an important role generally for the ratings of psycho-social factors, annoyance and distraction. Subjects' annoyance in the third mood rating was affected significantly by task types $(p=0.041)$. The combination of workstation and task types also showed a significant effect on annoyance ratings in the fourth mood rating $(\mathrm{p}=0.023)$. Task types distracted subjects statistically significantly in the second $(\mathrm{p}=0.004)$ and in the third mood ratings $(\mathrm{p}=0.021)$. Generally, subjects in the workstation with 6 foot partitions exposed to office sounds without speech expressed high annoyance and distraction. 


\section{SUMMARY AND CONCLUSIONS}

In keeping with previous research findings, simple tasks were not affected by the level of workspace enclosure or the type of distracting sounds. However, when native speaking occupants were given complex tasks, the value of fully enclosed workstations on task performance was statistically significant when compared to workstations with lower partitions. The mean score under fully enclosed workstations was 13.38 percent and 9.15 percent higher than that under 4 foot partitions and 6 foot partitions respectively. Moreover, occupants in closed workstations with office sounds without speech gave higher mood ratings to sociableness-indicating that closed individual offices may offer important contributions to collaborative work as well as individual productivity. This is a critical finding for the design community that at present is focusing on highly open plan designs in an effort to increase collaboration without recognizing the prevalence of complex tasks. Given that this performance did not measure an acoustic reduction increase implies that either noise levels below 45 $\mathrm{dBA}$ at the receiver will not have a significant effect, or that visual distraction is the major factor in performance and mood. Future studies may include noise levels of more than $45 \mathrm{dBA}$ and paper walls the same heights as the full enclosures.

\section{REFERENCES}

American Society of Heating, Refrigerating and Air-Conditioning Engineers (ASHRAE), Inc. (2001). Chapter 7. Sound and Vibration. In: ASHRAE. Handbook Fundamentals SI Edition 2001. Atlanta, GA: ASHRAE, 7.9-7.11.

American Society of Interior Design (ASID), Armstrong World Industries, Inc., Dynasound, Inc., Miliken \& Co. and Steelcase Inc. (1996). Sound Solutions: Increasing Office Productivity Through Integrated Acoustic Planning And Noise Reduction Strategies. Washington, D.C.: ASID.

Banbury, S. and Berry, D. C. (1997). Habituation and dishabituation to speech and office noise. Journal of Experimental Psychology: Applied, 3(3), 181-195.

Becker, F. and Sims, W. (2001). Offices That Work: Balancing Communication, Flexibility and Cost [online]. Cornell University International Workplace Studies Program. Available from: http:// iwsp.human.cornell. edu/file_uploads/ offices1_1238256905.pdf [Accessed 21 October 2012]

Block, L. K. and Stokes, G. S. (1989). Performance and Satisfaction in Private versus Nonprivate Work Settings. Environment and Behavior, 21(3), 277-297.

Brill, M., Weidemann, S. and the BOSTI Associates (2001). Disproving Widespread Myths about Workplace Design. Jasper, IN: Kimball International.

Cerami, V. V. (1979). Sound Control in the Open Office: A Guide to Speech Privacy. Muskegon, MI: Shaw-Walker Company.

Croome, D. J. (2000). Creating the Productive Workplace. London; New York: E \& FN Spon.

Davenport, T. H. and Prusak, L. (1998). Working knowledge : how organizations manage what they know. Boston: Harvard Business School Press.

Egan, M. D. (2007) Architectural Acoustics. Fort Lauderdale, FL: J. Ross Publishing
Gamberale, F., Iregren, A. and Kjellberg, A. (1989). SPES: the computerized Swedish Performance Evaluation System: background, critical issues, empirical data, and a users' manual. Solna Sweden: Arbetsmiljöinstitutet.

Gevins, A., Smith, M. E., Leong, H., McEvoy, L., Whitfield, S., Du, R. and Rush, G. (1998). Monitoring Working Memory Load during Computer-Based Tasks with EEG Pattern Recognition Methods. Human factors: the Journal of the Human Factors Society, 40(1), 13.

Hancock, P. A. (1987). Human Factors Psychology. New York, NY: Elsevier Science Publishing Company, Inc.

Hart, S. G. and Staveland, L. E. (1988). Development of a multidimensional workload rating scale: Results of empirical and theoretical research. In: P. A. Hancock and N. Meshkati, eds., Human Mental Workload. Amsterdam: North-Holland Press. 239-250

Horgen, T. H., et al. (1999). Excellence by design: transforming workplace and work practice. New York, NY: John Wiley \& Sons, Inc.

Hua, Y., Loftness, V., Heerwagen, J., and Powell, K. M. (2011). Relationship between Workplace Spatial Settings and OccupantPerceived Support for Collaboration. Environment and Behavior, 43(6), 807-826.

Jones, D. M., Madden, C., and Miles, C. (1992). Privileged Access by Irrelevant Speech to Short-term Memory: The Role of Changing State. The Quarterly Journal of Experimental Psychology, 44A (4), 645-669.

Jones, D. M. and Smith, A. P. (1992). Handbook of Human Performance. London; San Diego: Academic Press.

Loewen, L. J., and Suedfeld, P. (1992). Cognitive and arousal effects of masking office noise. Environment \& Behavior, 24(3), 381395.

Memoli, F. (1990). General Offices: Planning. In: J. D. Chiara and J. H. Callender, eds. Time-Saver Standards for Building Types. New York, NY: McGraw-Hill, 880-884.

Ng, C. F. (1989). Office Worker Performance and Satisfaction: The Effects of Office Noise and Individual Characteristics. Doctoral Dissertation. University of Victoria.

Salame, P. (1982). Disruption of Short-Term Memory by Unattended Speech: Implications for the Structure of Working Memory. Journal of Verbal Learning and Verbal Behavior, 21, 150-164.

Sundstrom, E., Town, J.P., Rice, R.W. and Osborn, D.P. (1994). Office noise, satisfaction, and performance. Environment \& Behavior, 26(2), 195-222.

Witterseh, T. (2001). Environmental Perception, SBS Symptoms and the Performance of Office Work under Combined Exposures to Temperature, Noise and Air Pollution. Doctoral Dissertation. Technical University of Denmark, Denmark.

Yerkes, R. M. and Dodson, J. D. (1908). The Relation of Strength of Stimulus to Rapidity of Habit Formation. Journal of Comparative Neurology \& Psychology, 18, 459-482.

(Received October 22, 2012/Accepted January 17, 2013) 